\title{
Untangling the transmission dynamics of primary and secondary vectors of Trypanosoma cruzi in Colombia: parasite infection, feeding sources and discrete typing units
}

Carolina Hernández ${ }^{1,2}$, Camilo Salazar ${ }^{3}$, Helena Brochero ${ }^{4}$, Aníbal Teherán ${ }^{5}$, Luz Stella Buitrago ${ }^{6}$, Mauricio Vera ${ }^{7}$, Hugo Soto ${ }^{8}$, Zulibeth Florez-Rivadeneira ${ }^{9}$, Sussane Ardila ${ }^{10}$, Gabriel Parra-Henao ${ }^{11}$ and Juan David Ramírez ${ }^{1 *}$

\begin{abstract}
Background: Trypanosoma cruzi is the causative agent of Chagas disease. Due to its genetic diversity has been classified into six Discrete Typing Units (DTUs) in association with transmission cycles. In Colombia, natural T. cruzi infection has been detected in 15 triatomine species. There is scarce information regarding the infection rates, DTUs and feeding preferences of secondary vectors. Therefore, the aim of this study was to determine T. cruzi infection rates, parasite DTU, ecotopes, insect stages, geographical location and bug feeding preferences across six different triatomine species.

Methods: A total of 245 insects were collected in seven departments of Colombia. We conducted molecular detection and genotyping of $T$. cruzi with subsequent identification of food sources. The frequency of infection, DTUs, Tcl genotypes and feeding sources were plotted across the six species studied. A logistic regression model risk was estimated with insects positive for T. cruzi according to demographic and eco-epidemiological characteristics.

Results: We collected 85 specimens of Panstrongylus geniculatus, 77 Rhodnius prolixus, 37 R. pallescens, 34 Triatoma maculata, 8 R. pictipes and 4 T. dimidiata. The overall T. cruzi infection rate was $61.2 \%$ and presented statistical associations with the departments Meta (OR: 2.65; 95\% Cl: 1.69-4.17) and Guajira (OR: 2.13; 95\% Cl: 1.16-3.94); peridomestic ecotope (OR: 2.52: 95\% Cl: 1.62-3.93); the vector species P. geniculatus (OR: 2.40; 95\% Cl: 1.51-3.82) and T. maculata (OR: 2.09; 95\% Cl: 1.02-4.29); females (OR: 2.05; 95\% Cl: 1.39-3.04) and feeding on opossum (OR: 3. 15; 95\% Cl: 1.85-11.69) and human blood (OR: 1.55; 95\% Cl: 1.07-2.24). Regarding the DTUs, we observed TCl (67. 3\%), Tcll (6.7\%), TcIII (8.7\%), TCIV (4.0\%) and TCV (6.0\%). Across the samples typed as Tcl, we detected TcIDom (19\%) and sylvatic Tcl (75\%). The frequencies of feeding sources were 59.4\% (human blood); $11.2 \%$ (hen); $9.6 \%$ (bat); $5.6 \%$ (opossum); $5.1 \%$ (mouse); $4.1 \%$ (dog); 3.0\% (rodent); 1.0\% (armadillo); and 1.0\% (cow).

Conclusions: New scenarios of T. cruzi transmission caused by secondary and sylvatic vectors are considered. The findings of sylvatic DTUs from bugs collected in domestic and peridomestic ecotopes confirms the emerging transmission scenarios in Colombia.
\end{abstract}

Keywords: Chagas disease, Secondary vectors, Trypanosoma cruzi, DTUs, Feeding sources, Colombia

\footnotetext{
* Correspondence: juand.ramirez@urosario.edu.co

${ }^{1}$ Grupo de Investigaciones Microbiológicas-UR (GIMUR), Programa de

Biología, Facultad de Ciencias Naturales y Matemáticas, Universidad del

Rosario, Bogotá 111221, Colombia

Full list of author information is available at the end of the article
} 


\section{Background}

Chagas disease caused by the protozoan parasite Trypanosoma cruzi, affects about six million people in Latin America. The main transmission mechanism is by insect vectors (stercoralian route). The insects responsible for vector transmission belong to the subfamily Triatominae (Hemiptera: Reduviidae), composed by approximately 140 species of 5 tribes [1]. The natural habitats of triatomines include palm trees, tree holes, cracks in rocks, small caves and other animal shelters [2]. The main vectors of T. cruzi in the Southern Cone countries are Triatoma infestans, Triatoma brasiliensis and Panstrogylus megistus; Rhodnius prolixus and Triatoma dimidiata in the Andean region and parts of Central America, and Triatoma dimidiata and T. barberi in Mexico [3]. A total of 26 species have been reported in Colombia; of these 15 have been shown to be naturally infected with $T$. cruzi [4]. Thus, $R$. prolixus and $T$. dimidiata are considered primary vectors, whereas P. geniculatus, T. maculata, $R$. pictipes and $R$. pallescens are considered secondary vectors, among others that have been found naturally infected with $T$. cruzi. In Colombia, there are approximately 436,000 people infected with $T$. cruzi, with an annual incidence of 5,250 vector-borne cases per population [5]. In addition, some studies revealed that species at greatest risk of transmission are $R$. prolixus, T. dimidiata, T. maculata and T. venosa [4]. However, vector control programs have focused on domiciled species as $R$. prolixus and T. dimidiata.

Trypanosoma cruzi transmission mostly occurs in three epidemiological cycles: sylvatic (enzootic), domestic and peridomestic, where the parasite circulates among triatomines, mammal reservoirs and human hosts. Around 180 sylvatic and synanthropic species of mammal have been described to date, which act as reservoirs of T. cruzi inhabiting places near human settlements [6]. Trypanosoma cruzi exhibits remarkable genetic diversity and has been classified by international consensus in six Discrete Typing Units (DTUs) (TcI-TcVI), plus a new genotype associated to anthropogenic bats (TcBat) [7]. The DTUs present associations with transmission cycles, geography, vector species and clinical manifestation to some extent [7-12]. The DTU with the broadest geographical distribution is $\mathrm{TcI}$ and due to its high genetic diversity has been divided into two genotypes, associated to domestic and sylvatic foci (TcIDom and Sylvatic TcI, respectively) [13-16].

Current molecular tools have improved the detection and genotyping of the parasite in the vectors as well as the identification of the vectors' feeding sources involved in the transmission of the parasite. However, in Colombia there is scarce information about the relationship between different vector species, $T$. cruzi infection and eco-epidemiological aspects of the transmission cycles. Control programs in this country have focused on domiciled vectors while epidemiological and scientific research has been restricted to the
Caribbean region. Therefore, the study of vectors in other areas of the country with a holistic perspective that considers $T$. cruzi infection rates, genotyping and feeding sources will help to identify the hosts and understand the dynamics of parasite transmission. This information will be useful to generate vector control strategies and accurate surveillance of Chagas disease. Thus, the objective of this study was to apply this holistic perspective to six triatomine species collected in different transmission cycles from seven departments in Colombia.

\section{Methods}

\section{Study area and collection of triatomines}

A total of 245 specimens corresponding to six species (85 P. geniculatus, 77 R. prolixus, 37 R. pallescens, 34 T. maculata, $8 R$. pictipes and $4 T$. dimidiata) were collected in the departments Guajira, Antioquia, Cesar, Norte de Santander, Meta, Casanare and Huila (Fig. 1; Additional file 1: Table S1). Insect capture in the sylvatic cycle was performed using two techniques: manual search and modified Noireau baited chicken traps in palms and distant to housing areas. Additionally, insects inside houses and in the peridomestic ecotope were collected. All insects were stored in separate jars, including a description of the site of collection and georeferenced using GPS. The insects were identified using taxonomic keys and stored in $100 \%$ ethanol until processing [17]. All of the specimens except $T$. dimidiata were collected from domestic, peridomestic and sylvatic cycles of transmission (Additional file 1: Table S1; Fig. 2).

\section{Molecular detection of $T$. cruzi and genotyping}

DNA extraction of the complete body of each insect was conducted using the ZR Tissue \& Insect miniprep DNA Zymo ${ }^{\mathrm{rm}}$ kit (Zymo Research, Irvine, USA), then endpoint qPCR was performed for detecting the satellite DNA of T. cruzi using primers cruzi1 (5'-AST CGG CTG ATC GTT TTC-3'), cruzi2 (5'-AAT TCC TCC AAG CAG CGG ATA-3') and cruzi3 probe (FAM-CAC ACA CTG GAC ACC AA-NFQ-MGB) using the conditions previously reported [18]. In the interpretation, since no $T$. cruzi DNA quantitation was performed, it is interpreted as positive DNA amplification in Cts $<38$ and negative amplification as absence. $12 \mathrm{~S}$ subunit ribosomal gene of triatomines was used as internal amplification control under the conditions and primers previously described [19]. Subsequently, the insects with positive results by qPCR were submitted to kinetoplast DNA amplification using primers 121 (5' $5^{\prime}$ AAA TAA TGT ACG GGK GAG ATG CAT GA-3') and 122 (5'-GGT TCG ATT GGG GTT GGT GTA ATA TA-3') to discriminate T. cruzi and $T$. rangeli infections as previously reported [20]. DNA from strains $\mathrm{MHOM} / \mathrm{CO} / 01 / \mathrm{DA}$ and $\mathrm{RHO} / \mathrm{CO} /$ 82/Durán were used as positive controls of T. cruzi and 


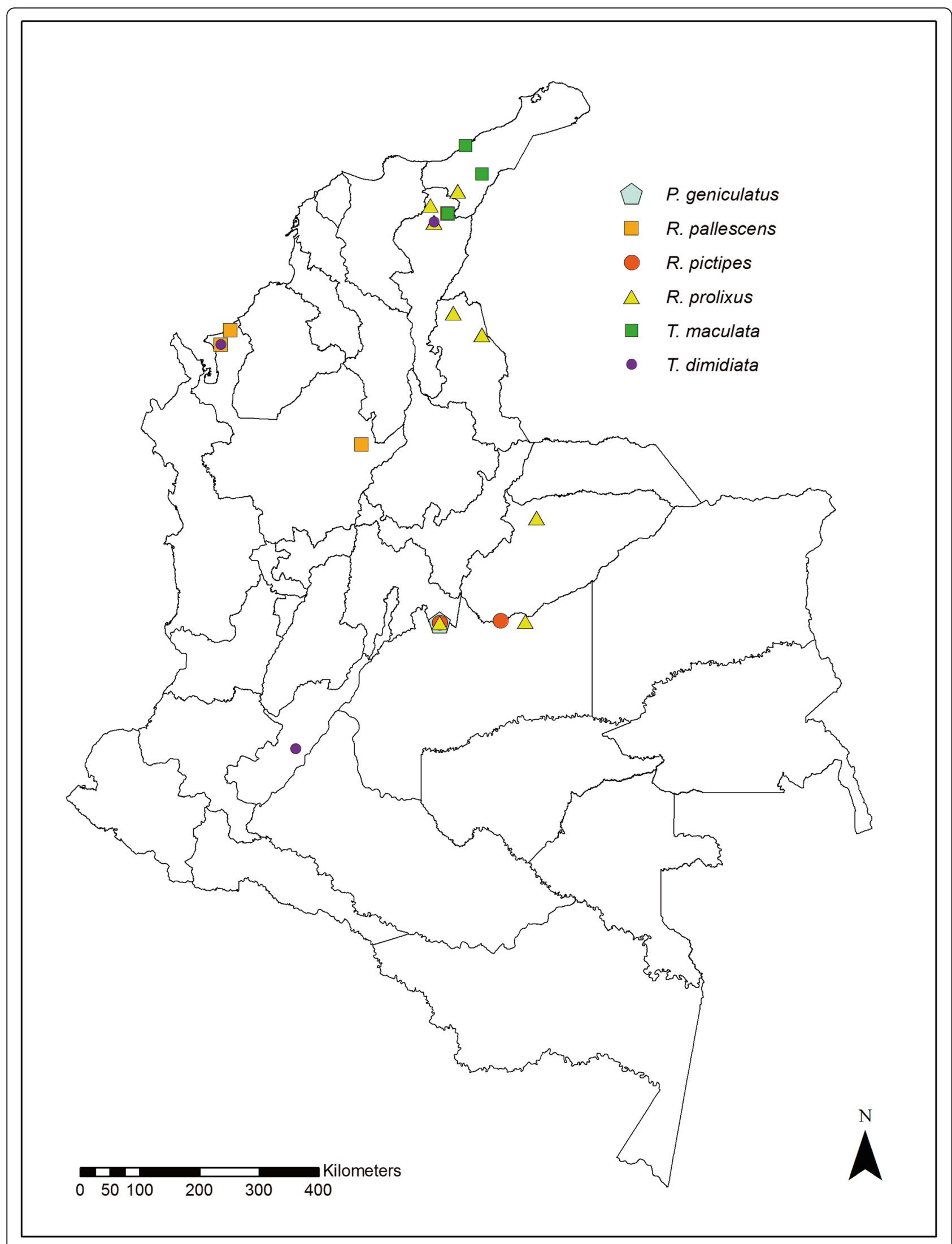

Fig. 1 Geographical distribution of 245 triatomines collected across Colombia and included in this study 


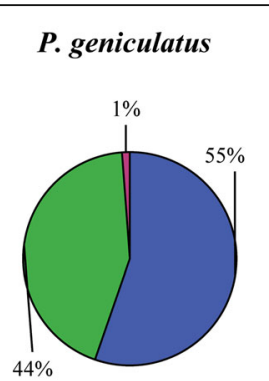

R. prolixus

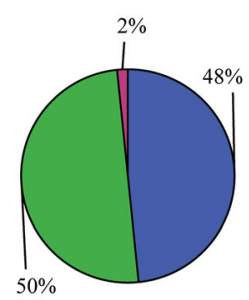

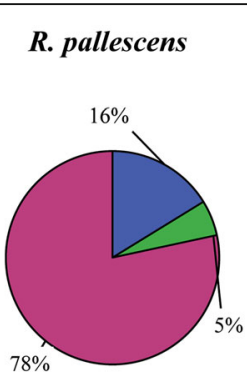

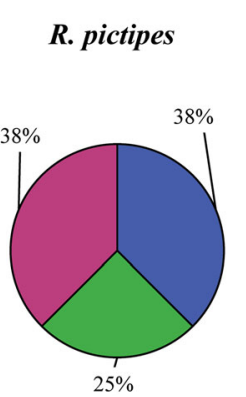

T. maculata

\section{Ecotope}

Domestic

Peridomestic

Sylvatic
T. dimidiata

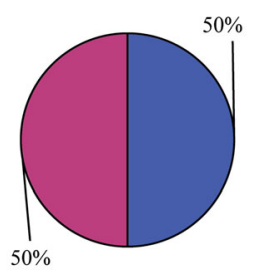

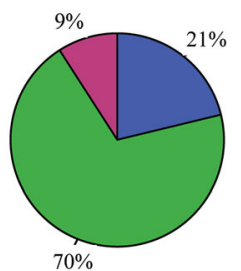

Fig. 2 Frequency of ecotopes for the species studied. Samples were collected in sylvatic, peridomestic and domestic ecotopes

T. rangeli, respectively. The identification of DTUs was accomplished by conventional PCR using the SL-IR, $18 \mathrm{~s}, 24 \mathrm{~s}$ and A10 targets as previously described [11, 21, 22]. We employed reference strains from each DTU as follows: TcIDom (DA), TcISylvatic (GC), TcII (Y), TcIII (CM17), TcIV (YLY), TcV (Tulahuen) and TcVI (CLBrener).

\section{Molecular characterization of blood sources}

All the 245 specimens were submitted to identification of feeding preferences by PCR-HRM (Polymerase chain reaction-High resolution melting) as previously reported [23]. Also, the feeding preferences were corroborated by direct sequencing of cytb using the primers CytbFw (5'CCC CTC AGA ATG ATA TTT GTC CTC A-3') and CytbRv (5'-CCA TCC AAC ATC TCA GCA TGA TGA AA-3'). The resulting sequences were edited in MEGA 6.0 [24] and submitted to BLASTn similarity search. This methodology allows the detection of 14 host species involved in the epidemiological cycles of Chagas disease as previously reported [23].

\section{Statistical analyses}

We calculated the frequency of T. cruzi infection, DTUs, TcI genotypes and feeding preferences across species and ecotopes (transmission cycles). To establish the association between the variables, Chi-square test was implemented with Monte Carlo adjustment with 10,000 simulations and G-test including pairwise comparison. Gtest was not applied in cases where the contingency table had zeros (Additional file 2: Table S2). Additionally, using an unconditional logistic regression, without including the intercept, the risk for infection with $T$. cruzi was estimated (OR, 95\% IC) according to the demographic and ecoepidemiological characteristics using EpiInfo V.3.5.4 software and $\mathrm{R}$ package version 3.3.1.1. Statistical significance was established with a $P$-value $<0.05$.

\section{Results}

Trypanosoma cruzi detection in six species of triatomines The information regarding the frequency of infection with $T$. cruzi by geographical location, ecotope and insect stage is shown in Table 1 . The overall T. cruzi infection rate was $61.2 \%(n=150)$. The species with the highest percentage of infection with $T$. cruzi was $P$. geniculatus, followed by $R$. prolixus and T. maculata (Fig. 3a). In addition, one $R$. prolixus was positive for $T$. rangeli.

The frequency of $T$. cruzi infection within each species was as follows: T. maculata: $67.6 \%(23 / 34)$; P. geniculatus: $70.6 \%$ (60/85); R. pallescens: $45.9 \%$ (17/37); R. prolixus: $55.8 \%$ (43/77); $R$. pictipes: $87.5 \%$ (7/8); and $T$. dimidiata: $25.0 \%(1 / 4)$ as shown in Fig. 3b. Association between species and the infection with $T$. cruzi was found $\left(\chi^{2}=13.35, d f=5, P=0.0171\right.$; G-test, $G=13.33, P$ $=0.0175)$, therefore statistical analysis was performed within each species using logistic regression (Table 2) and by Chi-square and G-test analysis (Additional file 2: Table S2; Additional file 3: Table S3). The species that showed association with the infection by $T$. cruzi were $P$. geniculatus and T. maculata. Panstrongylus geniculatus 
Table 1 Frequency of infection with T. cruzi by geographical location, ecotope and insect stage

\begin{tabular}{llll}
\hline Department & $n$ & $\%$ of infection with T. cruzi & $95 \% \mathrm{Cl}$ \\
\hline Meta & 69 & 46.0 & $38.0-53.9$ \\
Guajira & 32 & 21.3 & $14.7-27.8$ \\
Cesar & 24 & 16.0 & $9.5-21.1$ \\
Antioquía & 12 & 8.0 & $3.6-12.3$ \\
Norte de Santander & 9 & 6.0 & $2.2-9.8$ \\
Casanare & 3 & 2.0 & $0.4-5.7$ \\
Huila & 1 & 0.7 & $0.02-3.6$ \\
Ecotope & & & \\
Peridomestic & 68 & 45.3 & $39.7-56.1$ \\
Domestic & 52 & 34.7 & $28.7-44.5$ \\
Sylvatic & 22 & 14.7 & $9.5-21.4$ \\
Stage & & & $44.3-60.5$ \\
Female & 76 & 50.7 & $22.2-37.1$ \\
Male & 43 & 28.7 & $11.7-24.2$ \\
Nymph & 26 & 17.3 &
\end{tabular}

Abbreviation: $n$, number of positive samples

showed association with $T$. cruzi infection by the three statistical analyses. G-test revealed significant pairwise differences specifically with $R$. pallescens and $R$. prolixus. Trypanosoma maculata showed association with positive rate by Chi-square and logistic regression. Additionally, $R$. pictipes showed association only by Chi-square analysis. However, this is because the sample size is very small, which is reflected in the wide confidence interval in the logistic regression that invalidates the significant OR (Table 2; Additional file 2: Table S2; Additional file 3: Table S3). Furthermore, the association between species and ecotopes was statistically significant $\left(\chi^{2}=\right.$ 142.82, $d f=8, P<0.0001$; G-test, $G=123.17, P<0.0001)$. By analyzing G-pairwise comparison test, significant differences were observed among all species except for $R$. prolixus compared to $P$. geniculatus and $R$. pictipes compared to R. pallescens (Additional file 4: Table S4).

Regarding the infection with $T$. cruzi and the variables listed in Table 1, statistically significant association was evident with geographical location $\left(\chi^{2}=16\right.$, $d f=6, P=0.0066$; G-test, $G=16.93, P=0.0095)$. As for the geographical location, two departments (Guajira and Meta) exhibited a positive association with $T$. cruzi (Table 2). In both cases, these departments showed differences with departments Antioquia and Cesar; additionally, there were differences between Meta and Norte de Santander (Additional file 5: Table S5). No association with infection with $T$. cruzi was found regarding ecotope $\left(\chi^{2}=5.75, d f=2, P=0.0542\right.$; G-test, $G=$ 5.83, $P=0.0539)$ and life stage $\left(\chi^{2}=2.051, d f=2, P=\right.$
0.3586 ; G-test, $G=2.050, P=0.3864$ ). However, logistic regression detected association between the peridomestic ecotope, female stage and T. cruzi infection (Table 2).

\section{Feeding preferences across the six species of triatomines}

A total of 9 feeding sources were detected in 197 insects corresponding to six species. The frequencies were as follows: human blood: $59.4 \%$ (117); hen: 11.2\% (22); bat: 9.6\% (19); opossum: 5.6\% (11); mouse: 5.1\% (10); dog: 4.1\% (8); rodent: $3.0 \%$ (6); armadillo: $1.0 \%$ (2); and cow: $1.0 \%$ (2). Association of the feeding sources and T. cruzi infection was observed specifically with human blood and opossum $\left(\chi^{2}=12.917\right.$, $d f=8, P=0.1002$ ) (Table 2). Additionally, we evaluated the feeding preferences across 122 insects that were $T$. cruzi-positive and found human blood in $58.2 \%$ (71), hen in $7.4 \%$ (9), bat in $9.8 \%$ (12), opossum in $7.4 \%(9)$, mouse in $4.9 \%(6), \operatorname{dog}$ in $6.6 \%$ (8), rodent in $3.3 \%$ (4), armadillo in $0.8 \%$ (1) and cow in $1.6 \%$ (2). Regarding the feeding preferences by species, statistically significant association was observed $\left(\chi^{2}=99.56, d f=40, \quad P=0.0015\right)$. The insect vectors with the greatest variety of feeding sources were $P$. geniculatus, $R$. prolixus and $R$. pallescens (Fig. 4a). When feeding preferences were evaluated by ecotope, statistically significant association was found $\left(\chi^{2}=\right.$ 25.74, $d f=16, P=0.0468$ ) and the most common sources were human, hen, bat and opossum (Fig. 4b). Finally, the species positive for T. cruzi and bloodfeeding on humans are shown in Table 3.

\section{Trypanosoma cruzi DTUs and Tcl genotypes}

DTUs and TcI genotypes characterization was performed on 149 samples that were positive for $T$. cruzi. The frequencies were analyzed according to species and ecotope (Fig. 5a). We found cases of single and mixed infections observing TcI in $67.8 \%$ (101), TcII in 6.7\% (10), TcIII in $8.7 \%$ (13), TcIV in $4.0 \%$ (6), TcV in $6.0 \%$ (9) and mixed infections in $6.7 \%(10 / 149)$. No association was found between DTUs and species $\left(\chi^{2}=22.29, d f=20, P=0.3419\right)$, feeding sources (FD: $32, X^{2}=34.08, \mathrm{df}=32, P=0.6476$ ) and/or ecotopes $\left(\chi^{2}=13.88, d f=8, P=0.1733\right)$.

Regarding the TcI genotypes, we detected TcIDom in $19.0 \%(19 / 100)$, sylvatic TcI in $75.0 \%(75 / 100)$ and TcIDom/TcIsylvatic in $6 \%(6 / 100)$ of the mixed infections corresponded to TcI sylvatic + TcII, TcIDom + TcII, TcIsylvatic + TcIII, TcIsylvatic + TcIII + TcIV, TcIsylvatic + TcIV and TcIsylvatic $+\mathrm{TcV}$. We determined the infecting DTU and TcI genotypes discriminated by the species and ecotopes (Fig. 5b). Also, association between the TcI genotypes and the feeding sources $\left(\chi^{2}=94.21, d f=16, P\right.$ $=0.0137)$, ecotopes $\left(\chi^{2}=17.32, d f=4, P=0.0013\right)$ and species $\left(\chi^{2}=29.46, d f=10, P=0.0049\right)$. 
a

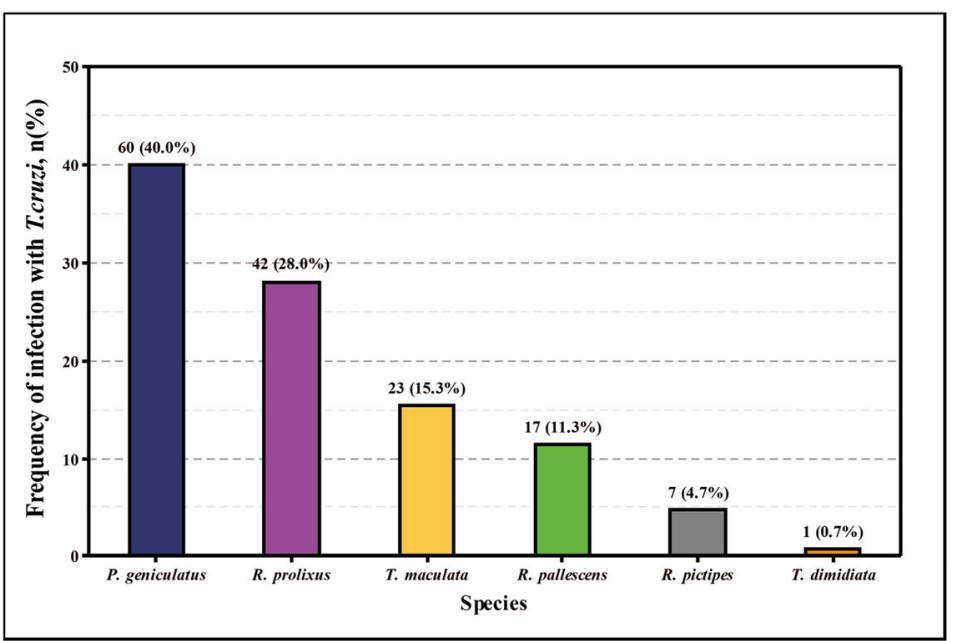

b

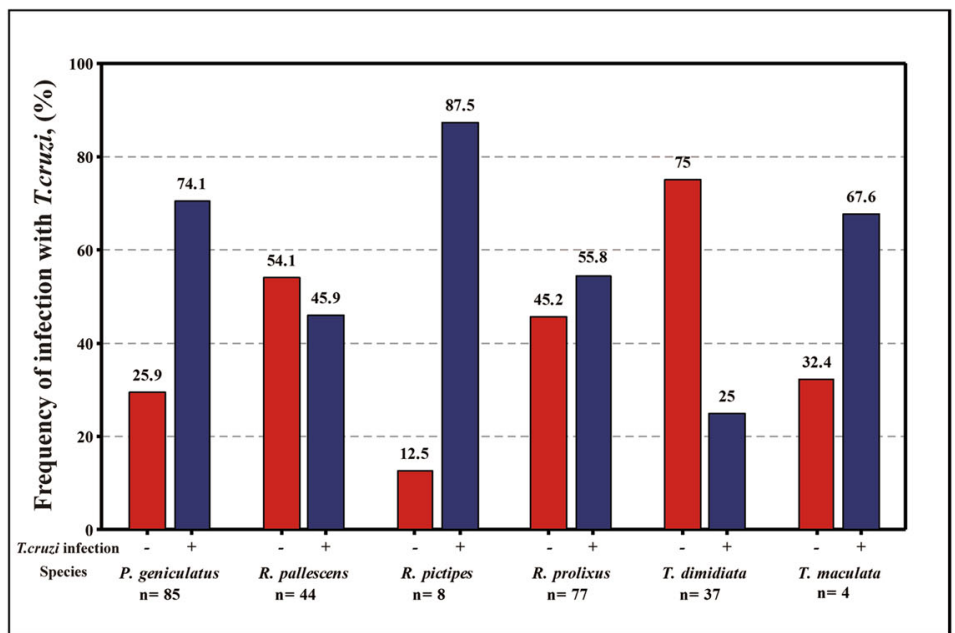

Fig. 3 Frequency of infection with T. cruzi in the triatomines collected. a Frequency of infection with T. cruzi in all samples. b Frequency of insects negative $(-)$ and positive $(+)$ for $T$. cruzi in all species collected

\section{Discussion}

Triatomine species collected in this study with the exception of $R$. prolixus and $T$. dimidiata are considered sylvatic and secondary vectors. Nevertheless, they were mainly collected in domestic ecotopes (Fig. 2), and there was an association between the ecotopes and species; and the main dietary source was human blood mainly in the domestic ecotope. Feeding sources with sylvatic reservoirs blood was the lowest in our dataset. These findings reflect the intrusion of vectors from sylvatic habitats to domestic habitats and their adaptation to the available feeding sources.

The high percentage of infection with $T$. cruzi and its relationship to the specific tested variables (peridomestic ecotope, feeding with human and opossum blood), together with the occurrence of sylvatic DTUs (sylvatic TcI and TcIII); P. geniculatus and T. maculata with high percentages of infection and feeding with human blood. They all suggest the existence of possible new transmission scenarios caused by intrusion of secondary vectors (mainly P. geniculatus and T. maculata in Meta and Guajira departments, respectively). The association of TcI genotypes with ecotopes, feeding sources and species is relevant given that the higher frequencies corresponded to sylvatic TcI, domestic ecotopes, feeding sources of humans, domestic and sylvatic animals. Therefore, since the statistically significant associations are the evidence of parasite population's movement from sylvatic to "domestic" populations with sylvatic strains is confirmed. This is of paramount relevance due to the impact of sylvatic T. cruzi in the acute phase and outbreaks of oral transmission. Additionally, statistically significant association between food sources (human and opossum) and T. cruzi infection reaffirms the potential of $D$. marsupialis as an important reservoir of the parasite $[25,26]$. 
Table 2 Variables associated with infection with T. cruzi across the insect vectors studied

\begin{tabular}{|c|c|c|c|}
\hline \multirow[t]{2}{*}{ Characteristic } & \multirow[b]{2}{*}{ Odds Ratio } & \multicolumn{2}{|c|}{ Infection with T. cruzi } \\
\hline & & $95 \% \mathrm{Cl}$ & $P$-value \\
\hline \multicolumn{4}{|l|}{ Species } \\
\hline P. geniculatus & 2.40 & $1.51-3.82$ & 0.0001 \\
\hline T. maculata & 2.09 & $1.02-4.29$ & 0.044 \\
\hline R. pictipes & 7.0 & $0.86-56-8$ & 0.068 \\
\hline R. prolixus & 1.20 & $0.76-1.88$ & 0.420 \\
\hline R. pallescens & 0.85 & $0.44-1.62$ & 0.622 \\
\hline T. dimidiata & 0.33 & $0.03-3.20$ & 0.341 \\
\hline \multicolumn{4}{|l|}{ Department } \\
\hline Casanare & 1.50 & $0.25-8.98$ & 0.657 \\
\hline Cesar & 1.00 & $0.56-1.78$ & 1.000 \\
\hline Guajira & 2.13 & $1.16-3.94$ & 0.016 \\
\hline Huila & 1.00 & $0.06-15.99$ & 1.000 \\
\hline Meta & 2.65 & $1.69-4.17$ & 0.0001 \\
\hline Norte de Santander & 0.82 & $0.34-1.97$ & 0.655 \\
\hline \multicolumn{4}{|l|}{ Feeding source } \\
\hline Armadillo & 1.00 & $0.06-15.99$ & 1.000 \\
\hline Canine $^{a}$ & 1473120.79 & $7.00->1.0 e^{12}$ & 0.957 \\
\hline Opossum & 3.15 & $1.85-11.69$ & 0.087 \\
\hline Hen & 0.60 & $6.26-1.40$ & 0.235 \\
\hline Human & 1.55 & $1.07-2.24$ & 0.022 \\
\hline Bat & 1.47 & $0.60-3.60$ & 0.400 \\
\hline Mouse & 1.50 & $5.42-5.32$ & 0.530 \\
\hline Rodent & 2.00 & $0.37-10.92$ & 0.424 \\
\hline \multicolumn{4}{|l|}{ Ecotopes } \\
\hline Sylvatic & 1.38 & $0.72-2.62$ & 0.332 \\
\hline Domestic & 1.24 & $0.82-1.86$ & 0.303 \\
\hline Peridomestic & 2.52 & $5.61-3.93$ & 0.0001 \\
\hline \multicolumn{4}{|l|}{ Stage } \\
\hline Female & 2.05 & $1.39-3.04$ & 0.0001 \\
\hline Male & 1.39 & $0.87-2.20$ & 0.165 \\
\hline Nymph & 1.18 & $0.67-2.09$ & 0.564 \\
\hline
\end{tabular}

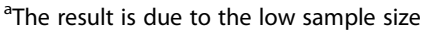

Significant values are indicated in bold

Our results are in accordance with other studies conducted in the Caribbean region of Colombia, which showed that secondary vectors play an important role in the different epidemiological transmission cycles of $T$. cruzi. These studies have shown that the frequency of patients with positive serology in the presence of sylvatic vectors is similar to the frequency in the presence of domestic vectors [4, 27]. Furthermore, our findings reinforce the role of $R$. prolixus as a domestic vector in Colombia given that among the triatomine species collected in this study, $R$. prolixus had the highest frequency of feeding with human blood and at the same time showed high rate of T. cruzi infection (33.8\%). The frequency of $R$. prolixus specimens collected in domestic habitats was $98.4 \%$ (Fig. 3a). The feeding sources of $R$. prolixus were mainly humans and domestic animals (Fig. 4a) and the DTUs detected were primarily associated with domestic cycles (TcI and TcII), and mostly infected with TcIDom (Fig. 5). These findings must be a support for the vector control programs in the country. Mainly, because most of the efforts have been focused on domestic vectors such as $R$. prolixus and T. dimidiata and our findings evidenced the potential risk of $T$. cruzi transmission by secondary vectors. Therefore, monitoring and control strategies specifically designed for sylvatic vectors are required in Colombia [28].

Surprisingly, we detected $\mathrm{TcV}$ in specimens of P. geniculatus and $R$. pictipes (sylvatic vectors). This DTU has been reported in domestic cycles from southern LatinAmerican countries [7, 29]. However, insects infected with $\mathrm{TcV}$ have been reported in domestic habitats in Colombia including some reports of human infections $[10,30]$. TcV associated with sylvatic cycles has been reported with a frequency of $3.5 \%$ [29]. Consistent with our findings of $\mathrm{TcV}$, a recent study [31] reported the presence of $\mathrm{TcV}$ in Colombian isolates obtained from $P$. geniculatus, $R$. prolixus, $T$. venosa and armadillos, using high-resolution markers: MLST, MLMT and ten mitochondrial markers. Messenger et al. [31] have also shown that the Colombian $\mathrm{TcV}$ isolates are due to migration processes from Southern Cone countries and not to local hybridization processes.

Triatoma maculata has a wide geographical distribution in Colombia. We observed a high invasion of domestic ecotopes by this species (Fig. 2), consistent with other studies in Colombia, Brazil and Venezuela where this species even presents morphological and genetic changes across individuals collected in domestic ecotopes [26, 27, 32-34]. Triatoma maculata has not been included in the vector control programs because its diet is mainly composed of bird blood [32, 35-37] and some studies have reported low frequency of infection in Brazil and Venezuela [36, 38]. By contrast, herein the frequency of T. cruzi infection was $67.6 \%$ and the percentage of feeding with human blood was $75.0 \%$ with the presence of TcIDom in some specimens collected in peridomiciliary habitats. Recent studies in Colombia and Venezuela have revealed infection frequencies between 38.0 and $75.0 \%$ and the presence of "TcIb" genotype that is associated with the peridomestic cycle $[26$, $27,33,34,39,40]$. Regarding the DTUs herein detected, most of the specimens were infected with TcI and TcIII (sylvatic DTUs) and domestic specimens harbored TcIII suggesting how T. maculata can connect domestic and sylvatic transmision cycles (Fig. 4). Our results and 

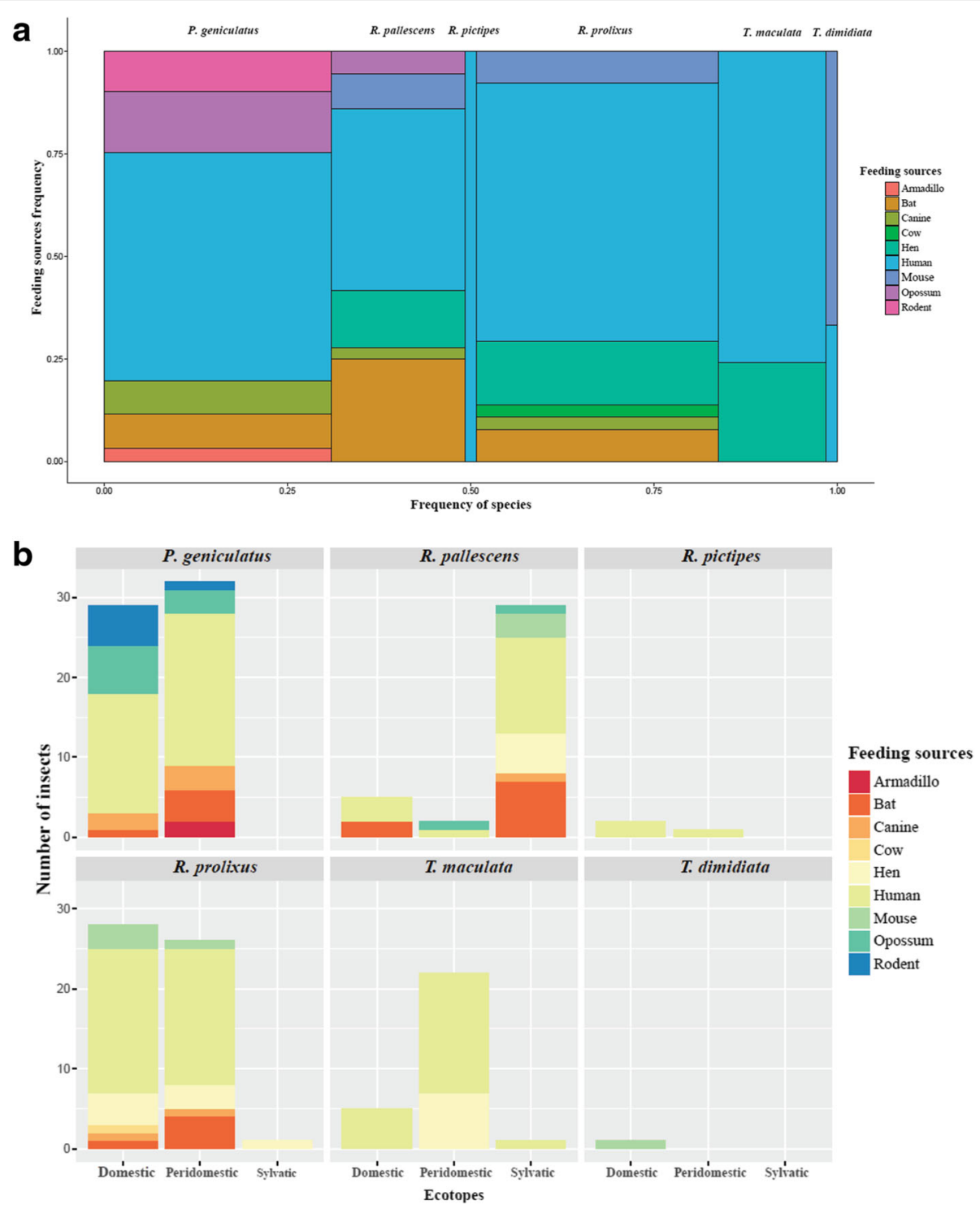

Fig. 4 Feeding sources in triatomines collected. a Feeding preferences across the six species of vector collected. $\mathbf{b}$ Feeding sources in species of triatomines collected by ecotope

previous reports highlight the relevance of $T$. maculata as a potential vector in Colombia suggesting the need to prioritize this species in vector control programs, and additionally, to be cautious about the potential risk of domiciliation that this species may have.

Panstrongylus geniculatus is the most widely distributed in Latin America species of the genus Panstrongylus [41]. In Colombia this species has the widest geographical distribution and is recorded in 25 departments including the Department of Meta [4]. In this study, most of the specimens were collected from the domestic ecotope (Fig. 2; Additional file 3: Table S3). Panstrongylus geniculatus is considered a sylvatic vector that inhabits in burrows primarily associated with armadillos, opossums, rodents and bats [41]. Accordingly, there are several reports in Latin America and Colombia demonstrating the intrusion of adult specimens of $P$. geniculatus in domestic habitats [42-45] and also findings of different nymphal stages in human dwellings mainly in Brazil, Venezuela and Colombia (Amalfi, Antioquia) [46-50]. Colonization in domestic habitats may be due to changes generated by housing construction and alteration of the ecosystems in the municipalities analyzed and/or by the attraction generated by the artificial light [51].

Our results showed $P$. geniculatus ranking first in T. cruzi infection (Fig. 3a; Table 2; Additional file 3: Table S3), similar to previous reports in Brazil, Venezuela 
Table 3 Frequency of infection with T. cruzi and human blood-feeding within each species

\begin{tabular}{llllc}
\hline Species & $n$ & $N$ & $\begin{array}{l}\text { Frequency of infection } \\
\text { with T. cruzi (\%) }\end{array}$ & $\begin{array}{l}\text { Frequency of infection } \\
\text { with T. cruzi and human } \\
\text { blood-feeding (\%) }\end{array}$ \\
\hline P. geniculatus & 60 & 85 & 70.59 & 27.06 \\
T. maculata & 23 & 34 & 67.65 & 47.06 \\
R. pallescens & 17 & 37 & 45.95 & 16.22 \\
R. prolixus & 43 & 77 & 55.84 & 32.47 \\
\hline
\end{tabular}

Abbreviations: $n$ Number of infected with T. cruzi, $N$ Total number

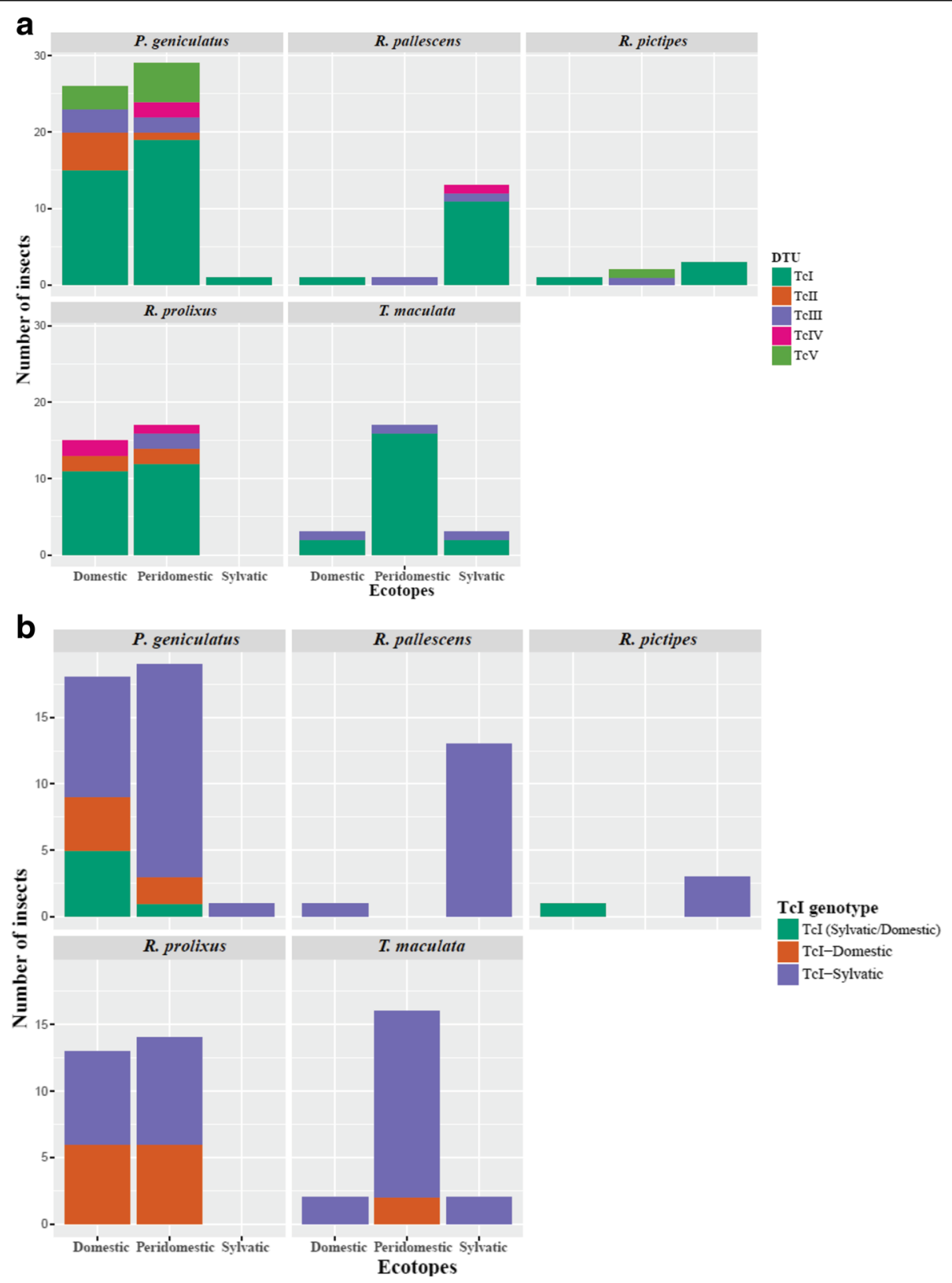

Fig. 5 Distribution of T. cruzi (DTUs) and Tcl genotypes according to species and ecotope. a Distribution of DTUs (Tcl-TcVl) in the six species collected and ecotopes. b Distribution of Tcl genotypes (TcIDom, Tcl sylvatic and Tcl sylvatic/TcIDom across species and ecotopes 
and the Colombian Caribbean region [40, 46, 48, 49]. We detected five DTUs in this species (TcI-TcV) that is in accordance with previous reports in Brazil, Venezuela and the Colombian Orinoco, and showing the interesting permissivity of this species facilitating the transmission of a wide variety of DTUs $[10,46,48,51]$. In contrast with other reports, we report a wide range of feeding sources with mammals of different epidemiological cycles and human blood. These results demonstrate the strong adaptive ability to different food sources and possibly explaining the high rate of infection and variety of DTUs. Human and canine blood constitute an important food source for $P$. geniculatus and similar to that observed in Venezuela, where also ten outbreaks of $T$. cruzi oral transmission involving this species were reported $[48,49,52]$. A small quantity of $P$. geniculatus fed on sylvatic sources (opossums, rodents, bats and armadillos) explaining the detection of sylvatic DTUs (TcI sylvatic, TcIII and TcIV) across our dataset [2, 41, 53] (Fig. 5a). All these findings could be a signal of an intrusive process from sylvatic ecotopes to domestic ones facilitated by adaptation, occurring in parallel in Colombia, Venezuela and Brazil [42-45], even accompanied by morphological changes in insects $[54,55]$. This pattern of ecotope intrusion explains the incrimination of $P$. geniculatus in oral outbreaks in Colombia [28, 56]; it is mandatory that surveillance strategies are deployed not only to avoid incrimination but also a possible domiciliation process.

Another sylvatic species is $R$. pallescens, given that its habitats are tree palms of Attalea butyracea and the invasion in domestic ecotopes is seen through intrusion $[2,57-60]$. Herein, insects were found in the three ecotopes and most specimens (both nymphs and adults) were collected in sylvatic habitats mainly in wine ( $A$. butyracea) and oil (Elaeis guineensis) palm trees, while 21.6\% (adults) were collected in domestic habitats. This is consistent with previous studies in Colombia [27, 57, 58, 60, 61] and Panama [40, 58, 62-65], where the percentage of $T$. cruzi infection is similar to our results. Moreover, it was observed that the main feeding source was human blood across the three ecotopes. This might be due to agriculture at the collection sites, where palms are nearby to homes and this can facilitate contact between the vectors and human hosts. We report that $R$. pallescens also fed on different mammals such as $D$. marsupialis in the peridomicile habitat and bats, mice and dogs in the sylvatic ecotope, showing an interplay between peridomestic and sylvatic cycles $[59,62-64,66,67]$. Finally, in the domestic ecotope the sylvatic TcI was only detected, showing that in fact, the specimens of $R$. pallescens might correspond to intrusions in homes from the sylvatic habitat. However, in contrast Cantillo et al. [58], detected "TcIb" in specimens of $R$. pallescens collected in domestic habitats, confirming that in Colombia there is a risk of $R$. pallescens intrusion supported by the high presence blood-feeding on humans and T. cruzi infection.

\section{Conclusions}

To the best of our knowledge, we conducted the first robust study sampling secondary vectors of $T$. cruzi in Colombia from different locations of the country. We used a broad variety of techniques to detect $T$. cruzi infection, DTUs, TcI genotypes and feeding sources that allowed us to understand the transmission dynamics in secondary vectors such as $P$. geniculatus, $T$. maculata and $R$. pallescens. Our findings reinforce the epidemiological relevance of these species and highlight the need to include them in the vector control programmes as well as in the entomological surveillance systems. Most of the secondary insects captured harbored sylvatic DTUs and fed on human blood highlighting the importance of these species. Our results demonstrate the need of the government to invest on the control of them in the light of their effort to interrupt T. cruzi transmission in Colombia.

\section{Additional files} Additional file 1: Table S1: Geographical coordinates and ecotopes in
vectors collected. (DOC $376 \mathrm{~kb}$ )

Additional file 2: Table S2: $T$. cruzi infection rates in the triatomine species studied. (DOCX $16 \mathrm{~kb}$ )

Additional file 3: Table S3: Pairwise G-test (T. cruzi infection rates by species). (DOCX $13 \mathrm{~kb}$ )

Additional file 4: Table S4: Pairwise G-test (Species vs Ecotopes). (DOCX $13 \mathrm{~kb}$ )

Additional file 5: Table S5: Pairwise G-test ( $T$. cruzi infection rates vs Geographical location). (DOCX $14 \mathrm{~kb}$ )

\section{Abbreviations}

DTU: Discrete typing unit; OR: Odds ratio; PCR-HRM: Polymerase chain reaction-high resolution melting; qPCR: Quantitative polymerase chain reaction

\section{Acknowledgements}

We thank C. Gonzalez from Universidad de los Andes for the construction of the map; Z. Cucunubá from the Department of Infectious Disease Epidemiology, Imperial College London, UK; O. Cantillo from Laboratorio Biología y Control de Enfermedades Infecciosas (BCEI), Universidad de Antioquia, Medellín; The Parasitology group and Red Chagas Colombia of Instituto Nacional de Salud, Bogotá, Colombia; NEGM and CG of "Programa ECOSALUD ETV Colombia, Centro de Estudios e Investigación en Salud (CEIS), Fundación Santa Fe de Bogotá, Bogotá, Colombia".

\section{Funding}

This work was funded by Institutional Funds (Dirección de Investigación, Universidad del Rosario) and "Departamento Administrativo Nacional de Ciencia y Tecnología de Colombia Francisco José de Caldas - COLCIENCIAS" by Convocatoria 727 de 2015, de Doctorados Nacionales.

\section{Availability of data and material}

The datasets supporting the conclusions of this article are included within the article and its additional files. 


\section{Authors' contributions}

JDR and $\mathrm{CH}$ wrote the manuscript. JDR, $\mathrm{CH}, \mathrm{AT}$ and $\mathrm{CS}$ analyzed the data. $\mathrm{CH}$ performed molecular techniques. HB, LSB, HS, ZFR, SR and GPH collected and identified insects. $\mathrm{HB}$ and $\mathrm{MV}$ contributed reagents/materials/analysis tools. All authors read and approved the final version of the manuscript.

\section{Competing interests}

The authors declare that they have no competing interests.

\section{Consent for publication}

Not applicable.

\section{Ethics approval and consent to participate}

Not applicable.

\section{Author details}

${ }^{1}$ Grupo de Investigaciones Microbiológicas-UR (GIMUR), Programa de Biología, Facultad de Ciencias Naturales y Matemáticas, Universidad del Rosario, Bogotá 111221, Colombia. ${ }^{2}$ Estudiante Doctoral, Doctorado Ciencias biomédicas y biológicas, Universidad el Rosario, Bogotá, Colombia. ${ }^{3}$ Biology Program, Faculty of Natural Sciences and Mathematics, Universidad del Rosario, Carrera. 24 No. 63C-69, Bogotá, DC 111221, Colombia. ${ }^{4}$ Facultad de Ciencias Agrarias, Universidad Nacional de Colombia, Bogotá, Colombia. ${ }^{5}$ Grupo de Investigación COMPLEXUS, Fundación Universitaria Juan N. Corpas, Bogotá, Colombia. 'Laboratorio de Salud Pública del Meta, Villavicencio, Colombia. ${ }^{7}$ Ministerio de Salud y protección Social, Bogotá, Colombia. ${ }^{8}$ Laboratorio de Salud Pública del Cesar, Valledupar, Colombia. ${ }^{9}$ Laboratorio de Salud Pública, Secretaría de Salud de La Guajira, La Guajira, Colombia. ${ }^{10}$ Grupo de Entomología, Instituto Nacional de Salud, Bogotá, Colombia. ${ }^{11}$ Centro de Investigación en Salud para el Trópico, Universidad Cooperativa de Colombia, Santa Marta, Colombia.

\section{Received: 22 August 2016 Accepted: 22 November 2016} Published online: 01 December 2016

\section{References}

1. Bargues MD, Schofield CJ, Dujardin JP. Classification and phylogeny of the Triatominae. First Edition. American Trypanosomiasis. Elsevier Inc.; 2010. p. 117-47. Available from: http://dx.doi.org/10.1016/B978-0-12-384876-5. 00006-X.

2. Waleckx E, Gourbière S, Dumonteil E. Intrusive versus domiciliated triatomines and the challenge of adapting vector control practices against Chagas disease. Mem Inst Oswaldo Cruz. 2015;110(3):324-38.

3. Rassi A, Rassi A, Marcondes De Rezende J. American trypanosomiasis (Chagas disease). Infect Dis Clin North Am. 2012;26(2):275-91.

4. Guhl F, Aguilera G, Pinto N, Vergara D. Actualización de la distribución geográfica y ecoepidemiología de la fauna de triatominos (Reduviidae: Triatominae) en Colombia. Biomedica. 2007;27:143-62.

5. WHO. Weekly epidemiological record - Chagas diseases in Latin America: an epidemiological update based on 2010 estimates. 2015. p. 5-13.

6. Herrera L. Una revisión sobre reservorios de Trypanosoma (Schizotrypanum) cruzi (Chagas, 1909), agente etiológico de la Enfermedad de Chagas. Bol Malariol y Salud Ambient. 2010;50(1):3-15

7. Zingales B, Miles M, Campbell D, Tibayrenc M, Macedo AM, Teixeira MMG, et al. The revised Trypanosoma cruzi subspecific nomenclature: Rationale, epidemiological relevance and research applications. Infect Genet Evol. 2012;12(2):240-53.

8. Guhl F, Ramírez JD. Trypanosoma cruzi I diversity: Towards the need of genetic subdivision? Acta Trop. 2011;119(1):1-4.

9. Burgos JM, Begher SB, Freitas JM, Bisio M, Duffy T, Altcheh J, et al. Molecular diagnosis and typing of Trypanosoma cruzi populations and lineages in cerebral chagas disease in a patient with AIDS. Am J Trop Med Hyg. 2005; 73(6):1016-8.

10. Guhl F, Ramírez JD. Retrospective molecular integrated epidemiology of Chagas disease in Colombia. Infect Genet Evol. 2013;20:148-54

11. Ramírez JD, Guhl F, Rendón LM, Rosas F, Marin-Neto JA, Morillo C. Chagas cardiomyopathy manifestations and Trypanosoma cruzi genotypes circulating in chronic Chagasic patients. PLoS Negl Trop Dis. 2010;4(11), e899.
12. Messenger LA, Miles MA, Bern C. Between a bug and a hard place: Trypanosoma cruzi genetic diversity and the clinical outcomes of Chagas disease. Expert Rev Anti Infect Ther. 2015;13(8):995-1029.

13. Zumaya-Estrada F, Messenger L, Lopez-Ordonez T, Lewis MD, Flores-Lopez C, Martínez-lbarra AJ, et al. North American import? Charting the origins of an enigmatic Trypanosoma cruzi domestic genotype. Parasit Vectors. 2012; 5(1):226.

14. Llewellyn MS, Miles MA, Carrasco HJ, Lewis MD, Yeo M, Vargas J, et al. Genome-scale multilocus microsatellite typing of Trypanosoma cruzi Discrete Typing Unit I reveals phylogeographic structure and specific genotypes linked to human infection. PLoS Pathog. 2009;5(5), e1000410.

15. Ramírez JD, Guhl F, Messenger L, Lewis MD, Montilla M, Cucunuba Z, et al. Contemporary cryptic sexuality in Trypanosoma cruzi. Mol Ecol. 2012;21(17):4216-26.

16. Ramírez JD, Tapia-calle G, Guhl F. Genetic structure of Trypanosoma cruzi in Colombia revealed by a High-throughput Nuclear Multilocus Sequence Typing (nMLST) approach. BMC Genet. 2013;14:96.

17. Lent H, Wygodzinsky P. Revision of the Triatominae (Hemiptera, Reduviidae) and their significance as vectors of Chagas disease. Bull Am Mus Nat Hist. 1979;163:123-520

18. Duffy T, Cura Cl, Ramirez JC, Abate T, Cayo NM, Parrado R, et al. Analytical performance of a Multiplex Real-Time PCR Assay using TaqMan Probes for quantification of Trypanosoma cruzi satellite DNA in blood samples. PLoS Negl Trop Dis. 2013;7(1), e2000.

19. Uehara LA, Moreira OC, Oliveira AC, Azambuja P, Lima APCA, Britto C, et al. Cruzipain promotes Trypanosoma cruzi adhesion to Rhodnius prolixus midgut. PLoS Negl Trop Dis. 2012;6:12.

20. Ramírez JD, Guhl F, Umezawa ES, Morillo C, Rosas F, Marin-Neto J, et al. Evaluation of adult chronic Chagas' heart disease diagnosis by molecular and serological methods. J Clin Microbiol. 2009;47(12):3945-51.

21. Burgos JM, Diez M, Vigliano C, Bisio M, Risso M, Duffy T, et al. Molecular identification of Trypanosoma cruzi discrete typing units in end-stage chronic Chagas heart disease and reactivation after heart transplantation. Clin Infect Dis. 2010:51(5):485-95.

22. Villa LM, Guhl F, Zabala D, Ramírez JD, Urrea DA, Hernández DC, et al. The identification of two Trypanosoma cruzi I genotypes from domestic and sylvatic transmission cycles in Colombia based on a single polymerase chain reaction amplification of the spliced-leader intergenic region. Mem Inst Oswaldo Cruz. 2013;108(7):932-5.

23. Peña VH, Fernández GJ, Gómez-Palacio AM, Mejía-Jaramillo AM, Cantillo O, Triana-Chávez O. High-resolution melting (HRM) of the cytochrome B gene: A powerful approach to identify blood-meal sources in Chagas disease vectors. PLoS Negl Trop Dis. 2012;6:2.

24. Tamura K, Stecher G, Peterson D, Filipski A, Kumar S. MEGA6: Molecular evolutionary genetics analysis version 6.0. Mol Biol Evol. 2013;30(12):2725-9.

25. Deane MP, Lenzi HL, Jansen A. Trypanosoma cruzi: vertebrate and invertebrate cycles in the same mammal host, the opossum Didelphis marsupialis. Mem Inst Oswaldo Cruz. 1984;79:513-5.

26. Cantillo-Barraza O, Garcés E, Gómez-Palacio A, Cortés LA, Pereira A, Marcet $\mathrm{PL}$, et al. Eco-epidemiological study of an endemic Chagas disease region in northern Colombia reveals the importance of Triatoma maculata (Hemiptera: Reduviidae), dogs and Didelphis marsupialis in Trypanosoma cruzi maintenance. Parasit Vectors. 2015;8(1):482.

27. Cantillo-Barraza O, Chaverra D, Marcet P, Arboleda-Sánchez S, TrianaChávez O. Trypanosoma cruzi transmission in a Colombian Caribbean region suggests that secondary vectors play an important epidemiological role. Parasit Vectors. 2014;7(1):381.

28. Ramírez JD, Montilla M, Cucunubá ZM, Floréz AC, Zambrano P, Guhl F. Molecular epidemiology of human oral Chagas disease outbreaks in Colombia. PLoS Negl Trop Dis. 2013;7(2):1-7.

29. Brenière SF, Waleckx E, Barnabé C, Tibayrenc M, Kjellberg F, Ayala F, et al. Over six thousand Trypanosoma cruzi strains classified into Discrete Typing Units (DTUs): Attempt at an inventory. PLoS Negl Trop Dis. 2016;10(8), e0004792.

30. Hernández C, Cucunubá Z, Flórez C, Olivera M, Valencia C, Zambrano P, et al. Molecular diagnosis of Chagas disease in Colombia: Parasitic loads and Discrete Typing Units in patients from acute and chronic phases. PLoS Negl Trop Dis. 2016;10(9), e0004997.

31. Messenger LA, Ramirez JD, Llewellyn MS, Guhl FMM. Importation of hybrid human-associated Trypanosoma cruzi strains of southern South American origin, Colombia. Emerg Infect Dis. 2016;22:8. 
32. Luitgards-Moura JF, Vargas AB, Almeida CE, Magno-Esperança G, AgapitoSouza R, Folly-Ramos E, et al. A Triatoma maculata (Hemiptera, Reduviidae, Triatominae) population from Roraima, Amazon Region, Brazil, has some bionomic characteristics of a potential Chagas disease vector. Rev Inst Med Trop Sao Paulo. 2005:47(3):131-7.

33. García-Alzate R, Lozano-Arias D, Reyes-Lugo RM, Morocoima A, Herrera L, Mendoza-León A. Triatoma maculata, the vector of Trypanosoma cruzi, in Venezuela. Phenotypic and genotypic variability as potential indicator of vector displacement into the domestic habitat. Front public Heal. 2014;2:170.

34. Rojas ME, Várquez P, Villarreal MF, Velandia C, Vergara L, Morán-Borges YH, et al. An entomological and seroepidemiological study of Chagas' disease in an area in central-western Venezuela infested with Triatoma maculata (Erichson 1848). Cad saude publica/Minist da Saude, Fund Oswaldo Cruz, Esc Nac Saude Publica. 2008;24(10):2323-33.

35. Espinola $H$, Rodríguez Md BRT. Informaciones sobre la biología y el ciclo de vida de Triatoma maculata (Erichson, 1848) (Hemiptera, Reduviidae, Triatominae), en condiciones de laboratorio. Bol Dir Malariol San Amb. 1981;21:141-2.

36. Tonn R, Otero E, Mora H, Carcavallo R. Aspectos biológicos,ecológicos y distribución geográfica de Triatoma maculata (Erichson, 1848), (Hemiptera, Reduviidae), en Venezuela. Bol Dir Malariol San Amb. 1978;18:16-24.

37. Feliciangeli M, Rabinovich J. Vital statistics of triatominae (Hemiptera: Reduviidae) under laboratory conditions. J Med Entomol. 1985;22:43-8.

38. Luitgards-Moura JF, Borges-Pereira J, Costa J, Zauza PL, Rosa-Freitas MG. On the possibility of autochthonous chagas disease in Roraima, Amazon Region, Brazil, 2000-2001. Rev Inst Med Trop Sao Paulo. 2005;47(1):45-54.

39. Gómez-Melendro EN, Hernández C, González-Uribe C, Brochero H. First record of Triatoma maculata (Erichson, 1848) (Hemiptera: Reduviidae: Triatomini) in the Municipality of Riohacha. La Guajira Colombia Front Public Heal. 2014;2(219):1-9.

40. Escalante ME, Gomez D, Silvera LA, Sánchez G, Venegas J. Detection of high percentage of Trypanosoma cruzi infection, the etiologic agent of Chagas disease, in wild populations of Colombian Caribbean triatomines. Acta Parasitol. 2015;60(2):315-21.

41. Patterson JS, Barbosa SE, Feliciangeli MD. On the genus Panstrongylus Berg 1879: Evolution, ecology and epidemiological significance. Acta Trop. 2009; 110(2-3):187-99.

42. Angulo VM, Esteban L, Luna KP. Attalea butyracea próximas a las viviendas como posible fuente de infestación domiciliaria por Rhodnius prolixus (Hemiptera: Reduviidae) en los Llanos Orientales de Colombia. Biomedica. 2012;32(2):277-85

43. Serrano O, Mendoza F, Suárez B, Soto A. Seroepidemiología de la enfermedad de Chagas en dos localidades del municipio Costa de Oro, Estado de Aragua, Venezuela. Biomédica Rev Del Inst Nac Salud. 2008; 28(1):108-15.

44. Maeda FY, Cortez C, Alves RM, Yoshida N. Mammalian cell invasion by closely related Trypanosoma species T. dionisii and T. cruzi. Acta Trop. 2012; 121(2):141-7.

45. Reyes-lugo M. Panstrongylus geniculatus Latreille 1811 (Hemiptera : Reduviidae : Triatominae), vector de la enfermedad de Chagas en el ambiente domiciliario del centro-norte de Venezuela. Medicina (B Aires). 2009;20(3):180-205.

46. Valente VC, Valente SA, Noireau F, Carrasco HJ, Miles MA. Chagas disease in the Amazon Basin: association of Panstrongylus geniculatus (Hemiptera: Reduviidae) with domestic pigs. J Med Entomol. 1998;35(2):99-103.

47. Feliciangeli MD, Carrasco H, Patterson JS, Suarez B, Martínez C, Medina M. Mixed domestic infestation by Rhodnius prolixus Stål, 1859 and Panstrongylus geniculatus (Latreille, 1811), vector incrimination, and seroprevalence for Trypanosoma cruzi among inhabitants in El Guamito, Lara State, Venezuela. Am J Trop Med Hyg. 2004;71(4):501-5.

48. Carrasco HJ, Torrellas A, García C, Segovia M, Feliciangeli MD. Risk of Trypanosoma cruzi I (Kinetoplastida: Trypanosomatidae) transmission by Panstrongylus geniculatus (Hemiptera: Reduviidae) in Caracas (Metropolitan District) and neighboring States, Venezuela. Int J Parasitol. 2005;35(13):1379-84.

49. Carrasco HJ, Segovia M, Londoño JC, Ortegoza J, Rodríguez M, Martínez CE. Panstrongylus geniculatus and four other species of triatomine bug involved in the Trypanosoma cruzi enzootic cycle: high risk factors for Chagas' disease transmission in the Metropolitan District of Caracas, Venezuela. Parasit Vectors. 2014;7(1):1003-28.

50. Maestre-Serrano R, Eyes-Escalante M. Actualización de la presencia y distribución de triatominos en el departamento del Atlántico-Colombia: 2003-2010. Bol Malariol y Salud Ambient. 2012;52(1):125-8.
51. Jácome-Pinilla D, Hincapie-Peñaloza E, Ortiz MI, Ramírez JD, Guhl F, Molina J. Risks associated with dispersive nocturnal flights of sylvatic Triatominae to artificial lights in a model house in the northeastern plains of Colombia. Parasit Vectors. 2015;8(1):600.

52. De Noya BA, Díaz-Bello Z, Colmenares C, Ruiz-Guevara R, Mauriello L, Muíoz-Calderón A, et al. Update on oral chagas disease outbreaks in Venezuela: Epidemiological, clinical and diagnostic approaches. Mem Inst Oswaldo Cruz. 2015;110(3):377-86.

53. Molinari J, Aldana E, Nassar JM. Panstrongylus geniculatus (Heteroptera: Reduviidae: Triatominae): Natural infection with Trypanosoma cruzi under cavernicolous conditions in Paraguaná Peninsula, Venezuela. J Cave Karst Stud. 2007;69(2):285-7

54. Aldana E, Heredia-Coronado E, Avendaño-Rangel F, Lizano E, Concepción JL Bonfante-Cabarcas R, et al. Morphometric analysis of Panstrongylus geniculatus (Heteroptera: Reduviidae) from Caracas City, Venezuela. Biomedica. 2011;31:108-17.

55. Mejía-Jaramillo AM, Fernández GJ, Montilla M, Nicholls RS, Triana-Chávez O. Sensibilidad al benzonidazol de cepas de Trypanosoma cruzi sugiere la circulación de cepas naturalmente resistentes en Colombia. Biomédica, Rev del Inst Nac Salud. 2012;32(2):196-205.

56. Soto H, Tibaduiza T, Montilla M, Triana-Chávez O, Suárez DC, Torres Torres $M$, et al. Investigación de vectores y reservorios en brote de Chagas agudo por posible transmisión oral en Aguachica, Cesar, Colombia. Cad Saúde Pública. 2014;30(4):746-56.

57. Romaña CA, Pizarro JC, Rodas E, Guilbert E. Palm trees as ecological indicators of risk areas for Chagas disease. Trans R Soc Trop Med Hyg. 1999; 93(Jan 2016):594-5.

58. Cantillo-Barraza O, Gómez-Palacio A, Salazar D, Mejía-Jaramillo AM, Calle J, Triana O. Distribution and ecoepidemiology of the triatomine fauna (Hemiptera: Reduviidae) in Margarita Island, Bolívar, Colombia. Biomedica. 2010;30(3):382-9.

59. Gottdenker NL, Chaves LF, Calzada JE, Saldaña A, Carroll CR. Host life history strategy, species diversity, and habitat influence Trypanosoma cruzi vector infection in changing landscapes. PLoS Negl Trop Dis. 2012;6(11):5-7.

60. Jaramillo N, Schofield CJ, Gorla D, Caro-Riaño H, Moreno J, Mejia E, et al. The role of Rhodnius pallescens as a vector of Chagas disease in Colombia and Panama. Res Rev Parasitol. 2000;60(3-4):75-82.

61. Parra-henao G, Angulo V, Jaramillo N, Restrepo M. Triatominos (Hemiptera: Reduviidae) de la Sierra Nevada de Santa Marta, Colombia. Aspectos epidemiológicos, entomológicos y de distribución. Rev CES Med. 2009;23(1):17-26.

62. Pipkin AC. Domiciliary reduviid bugs and the epidemiology of Chagas disease in Panama (Hemiptera: Reduviidae: Triatominae). J Med Entomol. 1968;5(1):107-24.

63. Pineda V, Montalvo E, Alvarez D, Santamaría AM, Calzada JE, Saldaña A. Feeding sources and trypanosome infection index of Rhodnius pallescens in a Chagas disease endemic area of Amador County, Panama. Rev Inst Med Trop Sao Paulo. 2008;50(2):113-6.

64. Calzada JE, Pineda V, Montalvo E, Alvarez D, Santamaría AM, Samudio F, et al. Human trypanosome infection and the presence of intradomicile Rhodnius pallescens in the western border of the Panama Canal, Panama. Am J Trop Med Hyg. 2006;74(5):762-5.

65. Hurtado LA, Calzada JE, Pineda V, González K, Santamaría AM, Cáceres L, et al. Conocimientos y factores de riesgo relacionados con la enfermedad de Chagas en dos comunidades panameñas donde Rhodnius pallescens es el vector principal. Biomedica. 2014;34:260-70.

66. De Vasquez AM, Samudio FE, Saldaña A, Paz HM, Calzada JE. Ecoepidemiological aspects of Trypanosoma cruzi, Trypanosoma rangeli and their vector (Rhodnius pallescens) in Panama. Rev Inst Med Trop Sao Paulo. 2004;46(4):217-22.

67. Zeledón R, Marín F, Calvo N, Lugo E, Valle S. Distribution and ecological aspects of Rhodnius pallescens in Costa Rica and Nicaragua and their epidemiological implications. Mem Inst Oswaldo Cruz. 2006;101(1):75-9. 